\title{
National Medication Safety Program at Ministry of Health in Saudi Arabia
}

\section{Yousef Ahmed Alomi*}

General Manager of General Administration of Pharmaceutical Care, Ministry of Health, Riyadh, Saudi Arabia

*Corresponding author: Yousef Ahmed Alomi, General Manager of General Administration of Pharmaceutical Care, Ministry of Health, P.O.BOX 100, Riyadh 11392, Riyadh, Saudi Arabia, Tel: +966504417712; E-mail: yalomi@gmail.com

Received date: September 08, 2015; Accepted date: September 09, 2015; Published date: September 12, 2015

Copyright: $\odot 2015$ Alomi YA. This is an open-access article distributed under the terms of the Creative Commons Attribution License, which permits unrestricted use, distribution, and reproduction in any medium, provided the original author and source are credited.

\section{Editorial}

Keywords: Medication safety; Medication errors; Pharmacovigilance; ADR; MOH; Saudi Arabia

\section{Introduction}

General Administration of Pharmaceutical Care of Ministry of Health (GAPD-MOH) in Saudi Arabia is responsible of implementing pharmaceutical care and related issues to 250 Hospitals and more than 2500 Primary Care centers including clinical Pharmacy and pharmacy Practice [1]. It had a vision stated "Achieving pharmaceutical, clinical, and electronic care, and inclusive human resources; along with cutting back on wastage and preventing all the medication-related problems in all over of the MOH's facilities" [2]. The mission is "To provide the best pharmaceutical and clinical care in high quality, modern technology, and the most reasonably-priced cost for the patients of the MOH's facilities" [3].

GAPD-MOH had established a strategic plan in 2012 for coming ten years 2013-2023 to improve pharmaceutical care at all hospital pharmacies, primary care centers pharmacies, and community pharmacies over all Saudi Arabia. This plan was established after reviewing strategic planning of Ministry of Health Saudi Arabia 2010-2020 [4,5]. The American Society of Health System Pharmacist (ASHP) strategic plan 2013-2015 [6,7], The American College of Clinical Pharmacy (ACCP) strategic plan 2013-2016 [8], and Saudi Pharmaceutical Society (SPS) [9]. GAPD$\mathrm{MOH}$ has established Five General Strategic Goals, that's included fourteen objectives, and fifty seven projects. The Strategic goals exploring as the following:

- Provide Complete Pharmaceutical Care with Safety and Best Practice

- Develop and Implement Pharmacy Human Resources

- Provide Complete Pharmacy Electronic Services

- Establish Innovation and Encouragement Culture at All Pharmacy Sitting

- Best Utilization Resources based on Pharmacoeconomics and Health Economics

\section{Strategies}

In the first Strategic goal there is one objective and four projects, the objective was about stated Patient Safety and Pharmacy staff and containing one big project applying national medication safety program at all pharmacy institution in Saudi Arabia. The National Medication Safety Program was launched in 2013; we have stated the program by initial awareness, assessment of medication safety in pharmacy institutions, figure out key performance indicators, gap analysis, and then action plan for this project and to be completed after five years.

During this medication safety journey, we gained a lot of experiences and several obstacles, and lots of challenges, we could overcome it while the program is running smoothly, expanding very quickly and good achievement $[10,11]$. We wish to explore what had been done during the journey by writing several topics in the coming issues and but not limited to the following

- Formulating of Medication Safety Program committees

- Updating of Medication Errors System

- Updating of Adverse drug reaction system

- Updating of Drug Quality Reporting System

- Basic Education Course of Medication Safety

- Medication Safety Training Center Self-Assessment

- Medication Safety Officer in Hospitals

- Human Resources of Medication Safety Program

- Assessment of Medication Safety Program in Hospitals

- Assessment of Medication Safety Program in Primary Health Centers

- Awareness material of Medication Safety Program

- Medication Safety of Anticoagulation Program

- Medication Safely for Pain Management Program

- Medication Safety Evaluation for new addition to $\mathrm{MOH}$ Formulary

- Drug Information Resources for Medication Safety

Medication Safety Program is very Essential to decrease and prevent drug related problems, decrease mortality and morbidity, and prevent unnecessary cost in health care system.

\section{References}

1. Pharmaceutical Care General Department - Director's Message (2015) Ministry of Health Portal, Kingdom of Saudi Arabia.

2. Pharmaceutical Care General Department - Vision (2015) Ministry of Health Portal, Kingdom of Saudi Arabia.

3. Pharmaceutical Care General Department - Mission (2015) Ministry of Health Portal, Kingdom of Saudi Arabia.

4. About the Ministry (2015) Ministry of Health Portal, Kingdom of Saudi Arabia.

5. http://www.moh.gov.sa/Portal/WhatsNew/Documents/OKIstragi260p.pdf

6. ASHP Announces New Strategic Plan-Pharmacist Organization Sets Strategic Priorities and Goals (2015) ashp pharmacists advancing healthcare.

7. http://www.ashp.org/DocLibrary/AboutUs/2015-ASHP-Strategic-Plan.pdf

8. ACCP Board (2013) the Strategic Plan of the American College of Clinical Pharmacy. 
Citation: Yousef Ahmed Alomi (2015) National Medication Safety Program at Ministry of Health in Saudi Arabia. J Pharmacovigil 3: e145. doi: 10.4172/2329-6887.1000e145

Page 2 of 2

9. Saudi Pharmaceutical Society (2015) The Representatives of Professional Pharmacists.

10. About the Ministry - Achievements (2015) Ministry of Health Portal, Kingdom of Saudi Arabia.
11. http://www.moh.gov.sa/en/Documents/Facts\%20\%20Achievements \%20Layout-\%20final\%20-Email\%20(sQ).pdf. 